\title{
OPTIMIZATION OF THE MAGNETIC CORE VOLUME IN A SINGLE-PHASE GRID-CONNECTED PV SYSTEM WITH ACTIVE AND REACTIVE POWER CONTROL
}

\author{
Kleber C. A. de Souza*, Walbermark M. dos Santos ${ }^{* *}$, Denizar C. Martins ${ }^{* *}$ \\ ${ }^{*}$ Federal Institute of Education, Science and Technology of Ceará, Brazil. \\ ${ }^{* *}$ Federal University of Santa Catarina, Power Electronic Institute, Brazil. \\ ksouza@inep.ufsc.br \\ walbermark@inep.ufsc.br \\ denizar@inep.ufsc.br
}

\begin{abstract}
This paper presents a method to minimize the losses and the magnetic cores volume in a singlephase active power filter based in a two stages gridconnected PV system. The proposed circuit injects PV generated power into the utility, and always acts as an active power filter to compensate load harmonics and reactive power such that the input power factor is very high independently of the solar radiation and the type of the load connected. In sunny days, the system processes all the reactive and active load power and the excessive power from the PV module can be fed to the utility. On the other hand, on cloudy days for instance, if the PV power is not enough, the system processes all the reactive load power and the shortage of active load power is supplemented by the utility. Besides, just using one current sensor, the control strategy is simple and of suitable for practical implementation.
\end{abstract}

Keywords: Single-Phase Circuits, Grid-Connected PV Systems and Active Power Filter.

\section{NOMENCLATURE}

PV: $\quad$ Photovoltaic.

HB ZVS-PWM: Half-Bridge Zero Voltage Switching Pulse Width Modulation.

$L_{r}: \quad$ Resonant inductor.

$C_{e 1}, C_{e 2}: \quad$ Output capacitors.

$C_{1}, C_{2}$ : Intrinsic capacitors of the switches $S_{w 1}, S_{w 2}$.

$V_{\text {imax }}: \quad$ Maximum input voltage.

$I_{o}: \quad$ Load current.

$I_{\text {omin }}: \quad$ Minimum load current.

$D_{\text {Imin }}: \quad$ Minimum duty cycle.

$n: \quad$ Transformer ratio.

$L: \quad$ Inductor between grid and inverter.

$I_{L}(t): \quad$ Inductor current.

$V_{L}(t): \quad$ Inductor voltage.

$V_{o}(t): \quad$ Output voltage.

$V_{i}(t): \quad$ Output voltage of the inverter.

$V_{t r i}: \quad$ Peak of the triangular carrier signal.

Manuscript received 18/03/2013. First revision on 18/06/2013, second revision on $06 / 11 / 2013$. Accepted for publication in $06 / 11 / 2013$, by recommendation of the Editor Henrique A. C. Braga.

$\begin{array}{ll}D: & \text { Duty Cycle. } \\ v_{\text {control }}: & \text { Control signal. } \\ G_{c d}: & \text { Utility voltage disturbance controller. } \\ Z: & \text { AC load impedance. } \\ I_{Z}: & \text { Load current. } \\ i_{L_{-} r e f:} & \text { Reference inductor current. } \\ i_{\mathrm{O}_{-} r e f(t)}: & \text { Difference between the reference } \\ I_{L r}: & \text { inductor current and the load current. } \\ q: & \text { Resonant inductor current. } \\ V_{S}: & \text { Output characteristic. } \\ T_{S}=1 / f_{S}: & \text { Transformer secondary voltage. } \\ P_{o}: & \text { Switching period. }\end{array}$

\section{INTRODUCTION}

Electricity is one of the most versatile energy forms, which best adapts to the needs of civilization in contemporary world. Its utilization reaches so far that it is hard to imagine a high developed society which does not use it in large scale. Large quantities of equipments are designed to run powered by electrical energy. We can say that the entire technology park, exception made, until now, when referring to transportation, is based upon electricity.

Mainly because of environmental reasons, since 80's decade, new forms of renewable energies are permanently in discussion, such as biomass, wind, solar etc. Therefore, its quantitative participation in global context is still low; what for some people might mean that these energies have a future business. Such idea ignores lots of factors of today's reality, at least in developing countries. In Brazil, for example, there is a considerable need to "quit a social debit" and solve energy problems of a bunch of unfortunate people and, if possible, without damaging the environment.

The use of photovoltaic systems as an alternative energy source has been largely discussed in the last decades due to the rapid growth of energy processing techniques utilized in power electronics. PV Stand-Alone systems were pioneers, because it was the more adequate and practical (less costs and weight) to provide the amount of energy necessary for long periods of staying in space during the space race. The same ones were largely used as energy sources for systems installed in remote areas. 


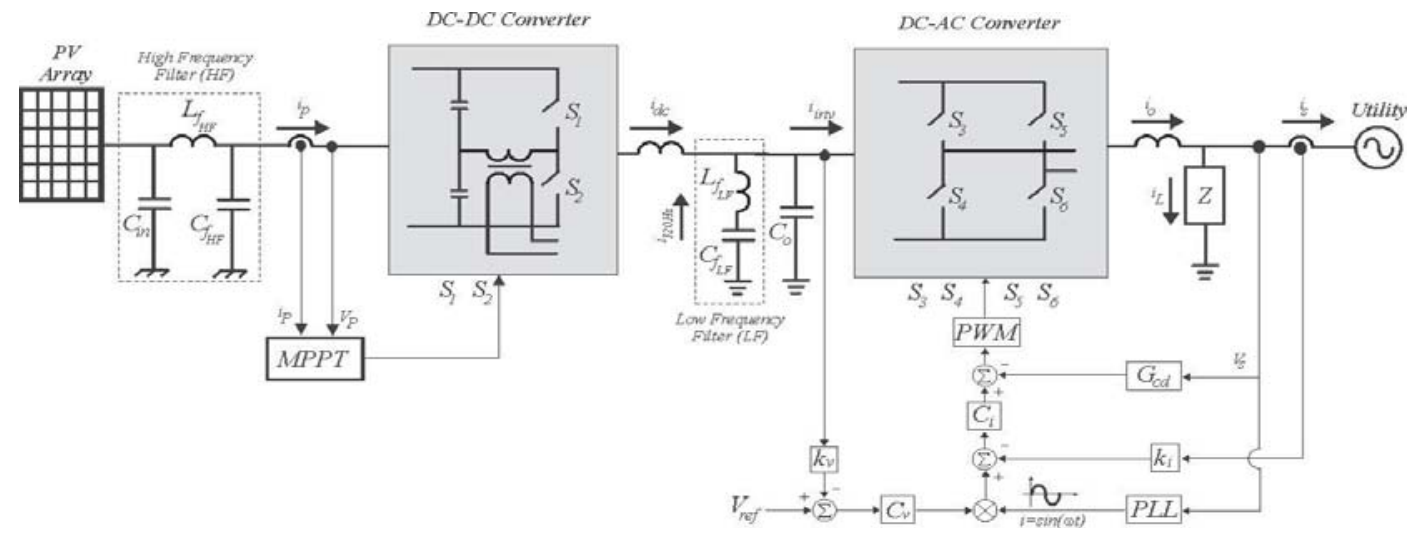

Fig. 1. Single-phase two stages Active Power PV System.

Systems connected directly to the energy company arose in the beginning of 90's and rapidly diffused in developed countries, strengthened mostly by solids investments of the government. The main advantage of this configuration is that, besides reducing costs, due to the fact that accumulators are not required, whenever it generates extra energy compared to the charge's consumption, this excess can be injected straight to the utility. When the system generates less than it is required to support the demand, the energy is extracted from the grid.

Thus, photovoltaic (PV) solar energy as an alternative resource is becoming feasible due to extensive researches and development work being conducted over a wide area [1], [2], [3], [4], [5] ,[6],[7],[8],[9] and [10].

Some researchers spent efforts in developing PV inverter systems with grid connection and active power filtering features using sensors to measure the load current [11], [12], [13] [14], [15], [16] and [17].

This paper presents a single-phase topology, without load current sensor, composed of a dc-dc converter cascaded to an inverter, as shown in Figure 1.

The system aims transferring photovoltaic (PV) power to the ac load and paralleled with the utility. The dc-dc converter is used to boost the PV voltage to a level higher than the peak of the utility voltage, such that the inverter provides the ac voltage without requiring the transformer.

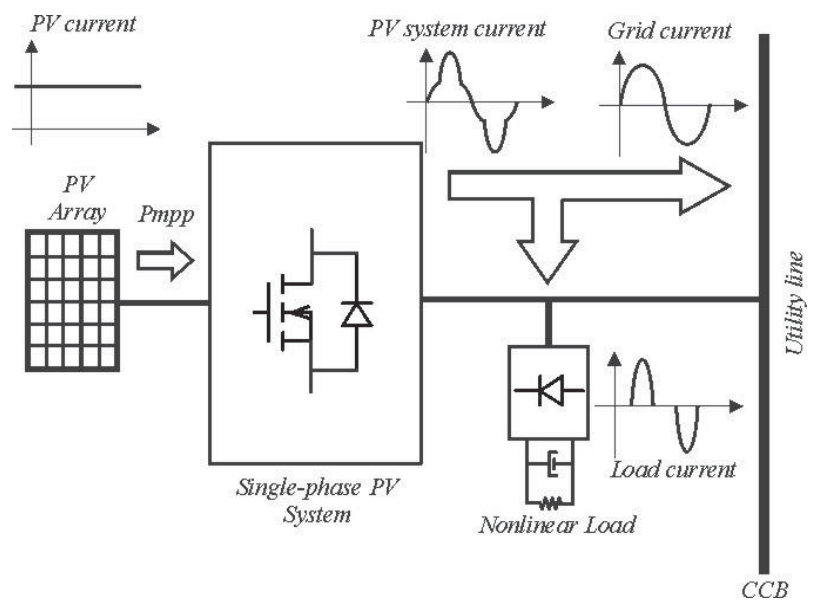

Fig. 2. Power flow of the system with nonlinear load.
Besides, a study to minimize the losses and the magnetic cores volume in the circuit is presented. Therefore, the efforts in the design of the dc-dc converter were focused in characteristics like: high efficiency, galvanic isolation, robustness, and facility to control.

The DC-DC converter is also responsible for tracking the maximum power point of the PV modules to fully utilize the PV power [18] and [19]. The power shortage from the PV module is supplemented by the utility grid. On the other hand, the eventual excessive power from the PV module to the load is fed to the utility. The balance of the power flow is controlled through the inverter. The inverter is also employed as an active power filter to compensate the load harmonics and the reactive power, such that the input power factor is very high (Figure 2).

\section{DESIGN PROCEDURES OF THE DC-DC CONVERTER}

The dc-dc converter power structure employed to boost the PV voltage and for tracking the maximum power point of the PV modules to fully utilize the PV power was the HalfBridge Zero Voltage Switching Pulse Width Modulation (DC-DC HB ZVS-PWM) asymmetrically driven converter [20]. Due to high voltage stresses on rectifier diodes [20], we chose to use two bridge rectifiers in series. Thus, it was necessary to use a transformer with double secondary winding. This strategy allows lower levels of stress and losses in rectifier diodes and, therefore, increases the efficiency of DC-DC stage. Figure 3 presents the power configuration of the DC-DC HB ZVS-PWM converter.

This converter is also called quasi-resonant for possessing a resonant stage during commutation period. This resonant stage occurs through a resonant inductor and the intrinsic capacitors of the switches. This kind of commutation allows the switches turn on and turn off under zero voltage.

The HB ZVS-PWM has been designed considering the reduction of the losses and of the volume of the magnetic cores. The use of ZVS technique, restricting the resonance to small intervals of commutation period, prevents the increase of switches voltage and current stresses. However, during the intervals in which happen changes in the inductor current, the rectifier diodes remain in short circuit and no power is transferred to the load. Only the resonant inductor $\left(L_{r}\right)$ receives energy during these intervals. As a consequence of 


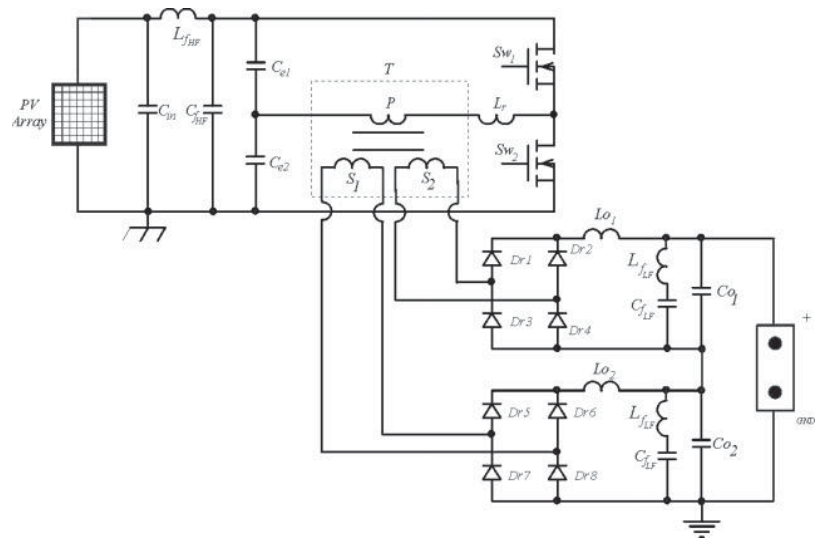

Fig. 3. Half-Bridge Zero Voltage Switching.

this phenomenon, there is a reduction in the effective time of existing voltage across the output terminals, resulting in a reduction of the value of the output voltage.

In order to obtain same average currents supplied by the system source (photovoltaic panel), during the operation stages DTs and $(1-D) T s$, it should be chosen an appropriate relationship between the capacitors $C_{e 1}$ and $C_{e 2}$ in the DCDC HB ZVS-PWM. The right value of the capacitor can be determined by (1) and (2) [16].

$$
\begin{gathered}
C e_{1}=\frac{P_{o}}{f_{s} \cdot \Delta V_{C_{i e q}} \cdot V i}(1-D) \\
C e_{2}=\frac{P_{o}}{f_{s} \cdot \Delta V_{C_{i e q}} \cdot V i} D
\end{gathered}
$$

The necessary condition for ZVS commutation is that the energy stored in the inductor $L_{r}$ is enough to discharge the intrinsic capacitor of the switch Sw1 $\left(C_{1}\right)$, completely loaded with the voltage $(1-D) V_{i}$ in the most critical case. Nevertheless, the most critical condition occurs when the energy stored in the capacitor $C_{1}$ is maximum and the current in the inductor is minimum. Equation (3) represents the voltage in the capacitor $C_{1}$ when in resonance with $L_{r}$.

$$
V_{C 1}(t)=(1-D) V i-I_{L r} \sqrt{\frac{L r}{C_{1}+C_{2}}} \cdot \operatorname{sen}\left(\omega_{0} t\right)
$$

As in the end of the resonance stage the voltage in the capacitor is zero, (3) can be rewritten as (4), where $V_{\text {imax }}$ is the maximum input voltage, $I_{\text {omin }}$ is the minimum load current for which the converter still operates with soft commutation, $D_{\text {Imin }}$ is the minimum duty cycle for this current, and $C_{1}, C_{2}$ represent the intrinsic capacitors of the switches $S_{w 1}, S_{w 2}$, respectively.

$$
L r_{1}(n)=\left[\frac{\left(1-D_{I \min }\right) \cdot V i_{\max }}{2 D_{I \min } \cdot I o_{\min }}\right]^{2}\left(C_{1}+C_{2}\right) n^{2}
$$

The output characteristic of the converter is given by (5).

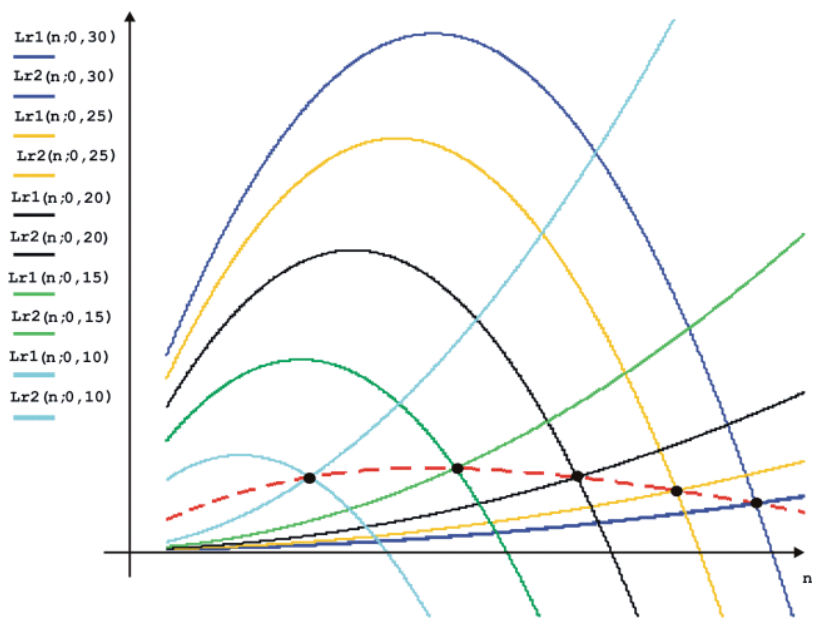

Fig. 4. Minimum inductor value for some $D_{\text {Imin }}$.

$$
q=\frac{n V_{o}}{V i}=2 D(1-D)-\frac{4 \cdot f_{s} \cdot L r \cdot I_{0}}{n V i}
$$

Solving (5) as function of $L_{r}$ obtains:

$$
L r_{2}(n)=\frac{n V i_{\text {máx }}\left[1-\left(1-D_{I \min }\right)^{2}\right]-2 n^{2} V s}{8 \cdot f_{s} \cdot I o_{\text {min }}}
$$

The response of the system, formed by equations (4) and (6), is obtained finding the point of intersection of two parables with opposite concavities, that cross in $(0,0)$. For that, a value should be attributed for $D_{\text {Imin }}$, and, for each attributed value, pair of curves and a point are found (see Figure 4).

Solving (5) as function of $D$, and substituting the result into(4), obtains:

$$
L r<\left[\frac{\left(\frac{1}{2}+\frac{1}{2} \sqrt{1-\frac{8 I o_{\min } \cdot L r \cdot f_{s}}{n V i_{\max }}-2 \cdot \frac{n \cdot V_{0}}{V i_{\max }}}\right) V i_{\max }}{\left(1-\sqrt{1-\frac{8 I o_{\min } \cdot L r \cdot f_{s}}{n V i_{\max }}-2 \frac{n \cdot V_{0}}{V i_{\max }}}\right) I o_{\min }}\right]^{2}\left(C_{1}+C_{2}\right)
$$

Another condition that has to be respected for the specification of the inductor refers to the maximum value of the duty cycle that the converter can work to guarantee operation in the asymmetrical way. The maximum value of $D$ should be smaller than 0.5 , it is a condition to be stipulated by the designer.

Returning to equation (5), it can be rewritten as it proceeds:

$$
D_{\text {máx }} \geq \frac{1}{2}-\frac{1}{2} \sqrt{1-2 \frac{4 \frac{I_{0}}{n} L r \cdot f_{s}}{V i_{\text {min }}}-2 \frac{n V_{o}}{V i_{\text {min }}}}
$$

Solving (8) as function of $L_{r}$ obtains the value that guarantees the asymmetrical operation of the converter for $D_{\max }$. 


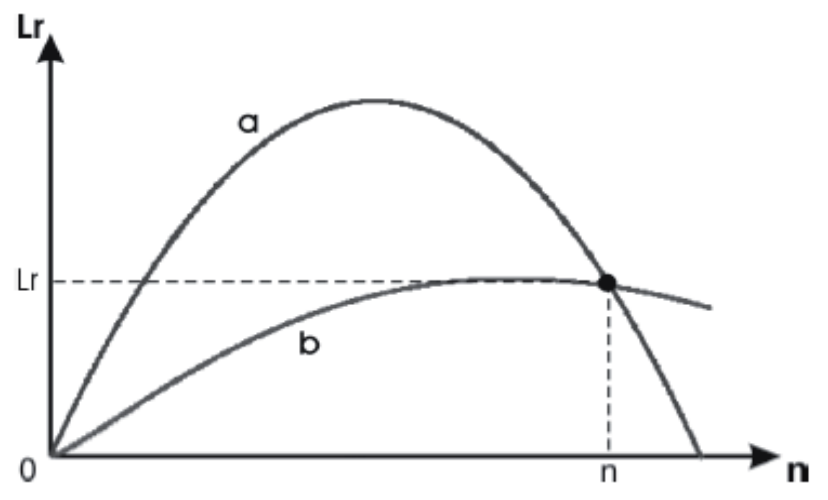

Fig. 5. Optimum adjusts for the resonant inductor and the transformer ratio for the DC-DC HB ZVS-PWM converter.

$$
\operatorname{Lr}(n) \leq\left[2 D_{\max }\left(1-2 D_{\max }\right)-\frac{V_{o} \cdot n}{V i_{\min }}\right]^{2} \frac{n V i_{\min }}{4 \cdot f s \cdot I_{0}}
$$

Solving numerically equations (7) and (9), we obtain the curves presented in Figure 5.

Based on these analysis, the conclusion is that the best choice for the values of the resonant inductor $\left(L_{r}\right)$ and of the transformer ratio $(n)$ is given by the intersection points between the curves obtained by (7) (curve b) and by (9) (curve a), according to Figure 5 [20].

From this methodology the transformer and resonant inductor were designed, having an average gain in losses of $5 \%$ and $10 \%$ in volume, compared to other similar converters.

\section{SYSTEM CONFIGURATION AND CONTROL STRATEGY}

Figure 6 presents the full bridge topology with the inductor $L$ connected between the grid $\left(V_{o}(t)\right)$ and the inverter, the capacitor $C_{i}$, in the structure input, representing the DC voltage source and a current source $\left(I_{i}(t)\right)$, that can be either the output of the DC-DC converter or an array of photovoltaic panels.

Considering the self-commutated inverter switching at high frequency and using Three-Level PWM technique, it is possible to represent the four equivalent circuits of the switching modes (Figure 7), defined by the combination of the switches possible states with the two possible directions of the output current.

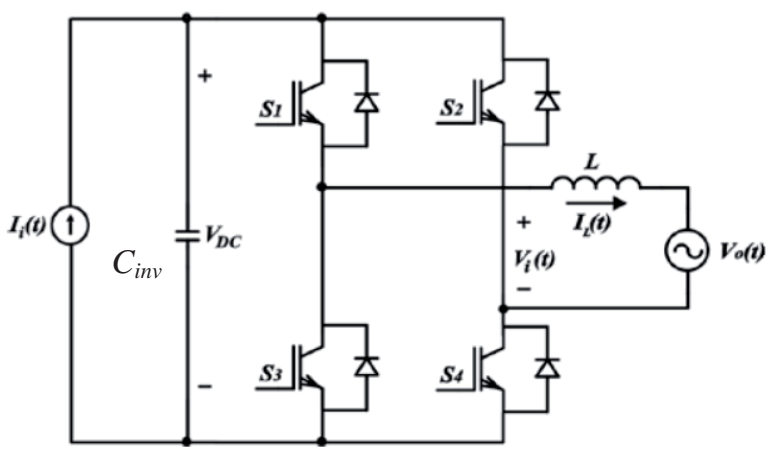

Fig. 6. Full bridge inverter.
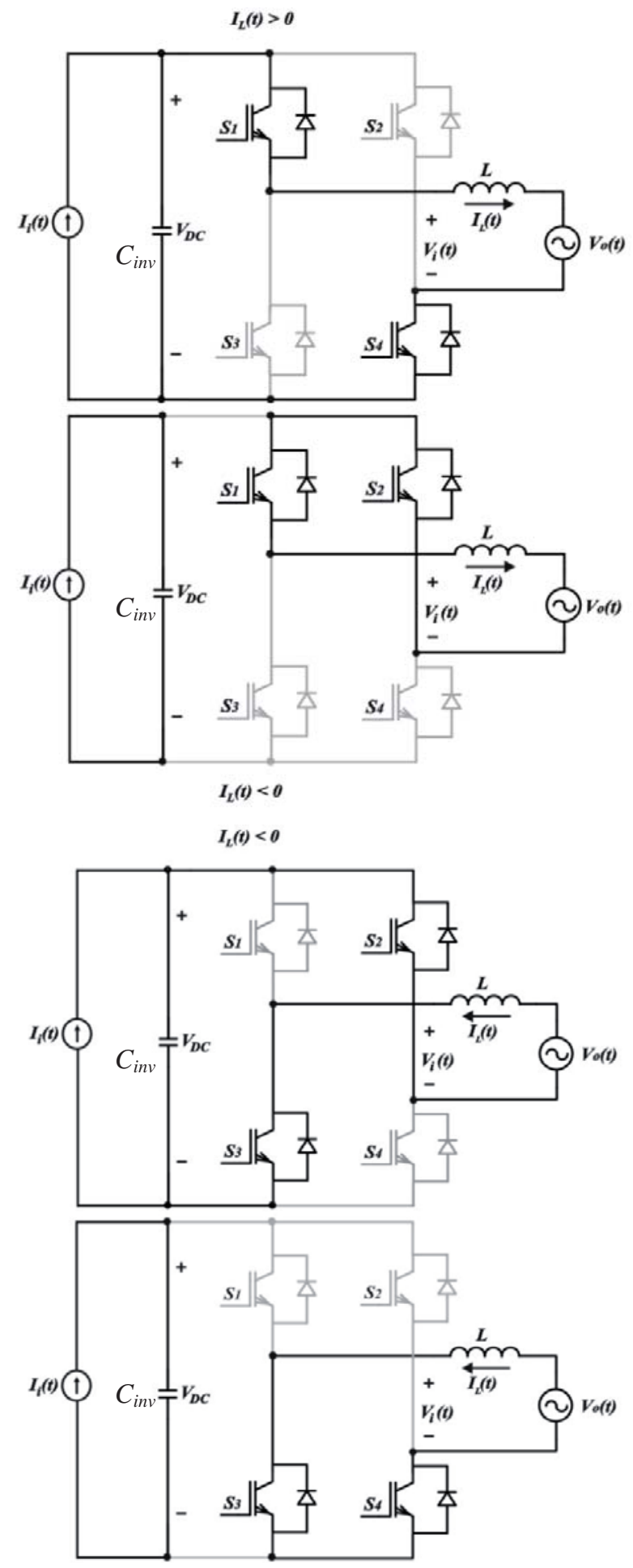

Fig. 7. Four equivalent circuits of the switching modes.

From the operational stages, it can be observed that when $I_{L}(t)>0$ and the switches $S_{1}$ e $S_{4}$ are on, voltage $V_{i}(t)$ has its polarity defined by the direction of the output current, with its absolute value equals to the input voltage $V_{D C}$, whose amplitude should be larger than the peak value of the output voltage, $V_{o}(t)$. In this manner, the voltage polarity across the inductor causes its current's absolute value to increase. During this stage, energy from the input source, $V_{D C}$, along with part of the energy stored in the inductor, is transferred to the grid. 


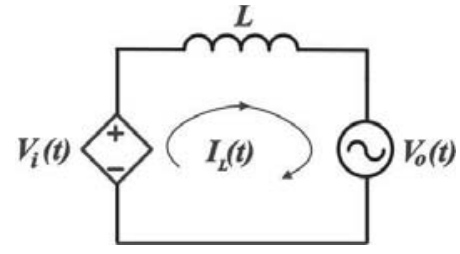

Fig. 8. Simplified equivalent inverter circuit.

When $I_{L}(t)>0$ and the switches $S_{1}$ and $S_{2}$ are on, voltage $V_{i}(t)$ is zero. In this case, the voltage polarity across the inductor is inverted, causing its current absolute value to decrease.

Indeed, the output current is controlled by imposing the derivative of the current through the inductor, or, put differently, by imposing the voltage across the inductor $L$. In this manner, the structure of the converter shown in Figure 6 can be represented, without loss of generality, as the controlled voltage source $V_{i}(t)$, presented in Figure 8 where the link inductors are represented by the inductor $L, V_{o}(t)$ is the utility voltage and $I_{L}(t)$ is the output PV system current.

In Figure 8 the energy flow is controlled by the current $I_{L}(t)$. However, this current is defined by the difference of voltage between the sources $V_{i}(t)$ and $V_{o}(t)$, applied across the impedance. In this case, as the impedance is a pure inductance, the current will be equal to the integral of the voltage across it.

As $V_{o}(t)$ is known, once it is the utility voltage itself, $V_{i}(t)$ is imposed and therefore $V_{L}(t)$. Thus:

$$
V_{L}(t)=V_{i}(t)-V_{o}(t)
$$

PWM defines a modulated signal composed of the reproduction of the modulating signal's spectrum, whose amplitude is defined by the modulation, added to harmonic components of frequencies that are multiples of the switching frequency. Ignoring the effect of the harmonic components of the switching frequency on voltage $V_{i}(t)$, once the inductor works as a low pass filter for the current, the voltage imposed across the inductor is represented simply by (10). Figure 9 shows the manner in which the converter allows the voltage to be imposed across the inductor, as shown in the equivalent circuit of Figure 8.

Indeed, the output current is desired to be a mirror of $V_{o}(t)$ as expressed in (11). Nevertheless, according to (12), the inductor voltage is the derivative of the current through itself. Therefore, (13) describes the voltage $V_{i}(t)$, which, in effect, is defined by the control loop, should present a sine, in order to null the effect of $V_{o}(t)$, and a cosine, which, by composition, will be the resulting voltage imposed across the inductor,

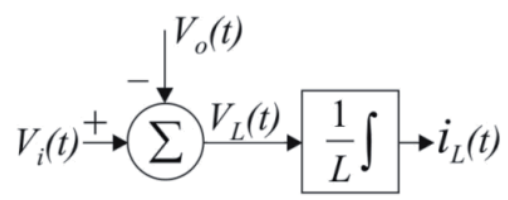

Fig. 9. Block diagram of the simplified equivalent circuit. therefore, guaranteeing a sinusoidal current. In practice, at the grid frequency, the inductor is a very small reactance, causing the voltage drop across the inductor to be much smaller than the utility voltage. In other words, the sine of $V_{i}(t)$ dominates the cosine, demonstrating that the demand on the current loop is much more in favor of annulling the "disturbance" of the utility voltage rather than to effectively control the output current.

$$
\begin{gathered}
I_{L}(t)=I_{r m s} \sqrt{2} \cdot \sin (\omega t) \\
V_{L}(t)=L \frac{d I_{L}(t)}{d t}=L \cdot I_{r m s} \cdot \sqrt{2} \cdot \omega \cdot \cos (\omega t) \\
V_{i}(t)=L \cdot I_{r m s} \cdot \sqrt{2} \cdot \omega \cdot \cos (\omega t)+V_{r m s} \sqrt{2} \cdot \sin (\omega t)
\end{gathered}
$$

In the classic control strategy, an internal current loop and an external loop to control the input voltage are implemented. The voltage loop defines the amplitude of the reference current by multiplying its control signal by a "waveform", which can be a sample of the output voltage or a digitally generated sinusoid, generating the output current reference. Figure 10 demonstrates how the classic control strategy is implemented, in which $V_{i}(t)$ is determined by the current error signal passing through the compensator. The error signal is the difference between a sample of the current and its reference. Figure 11 shows the same block diagram in a simplified way.

It is observed, however, that the output voltage $V_{o}(t)$ appears as a disturbance in the simplified traditional model.

Rewriting (10) as in (14):

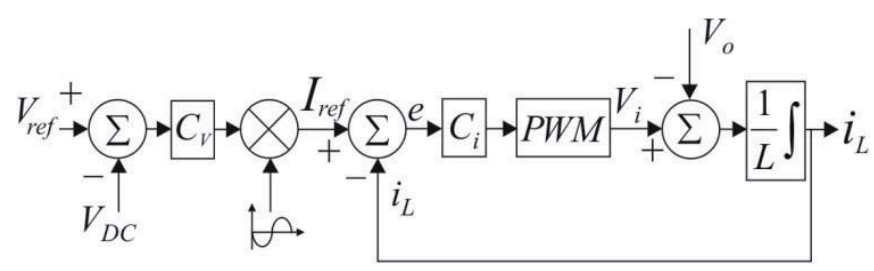

Fig. 10. Block diagram of classical control strategy current loop.

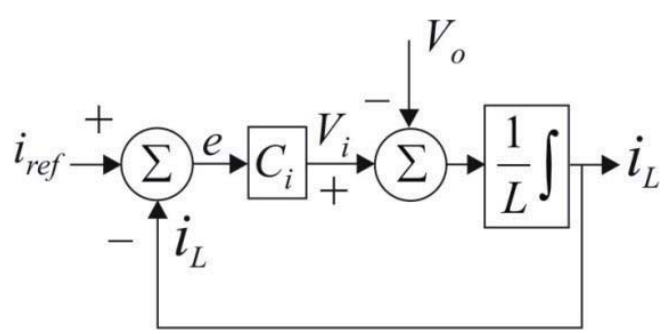

Fig. 11. Simplified block diagram of classical control strategy current loop. 


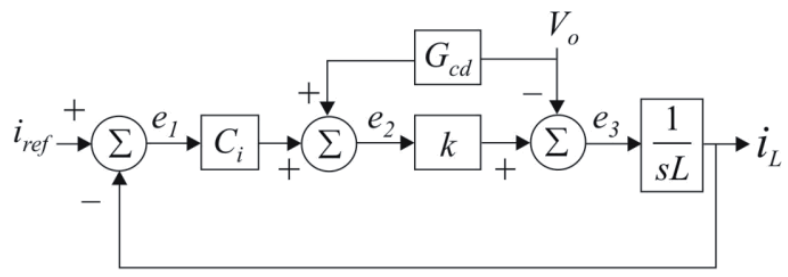

Fig. 12. Block diagram containing the feed-forward controller.

$$
L \frac{d i_{L}(t)}{d t}=k \cdot v_{\text {control }}(t)-V_{o}(t)
$$

The parameter $k$ is defined in (15).

$$
k=\frac{V_{D C}}{V_{t r i}}
$$

Where $V_{t r i}$ is the peak of the triangular carrier signal and $v_{\text {control }}$ is the control signal witch shapes the sinusoidal current to the utility line. From the block diagram, the current signal error is equal to.

$$
e(t)=i_{\text {ref }}(t)-i_{L}(t)
$$

Since a perfectly sinusoidal current to the utility line is a design goal, $e$ must naturally approach zero. Thus, deriving (16) and substituting (14) gives:

$$
\begin{gathered}
\frac{d e(t)}{d t}=0=\frac{d i_{r e f}(t)}{d t}-\frac{d i_{L}(t)}{d t} \\
v_{\text {control }}(t)=\frac{L}{k} \frac{d i_{r e f}(t)}{d t}+\frac{1}{k} V_{o}(t)
\end{gathered}
$$

As the disturbance is measurable, the utility voltage disturbance controller $G_{c d}$ is used to reduce de disturbed voltage component. The new block diagram that contains this feed-forward controller is presented in Figure 12. From Figure 12, it can be seen that:

$$
i_{L}=\frac{k C_{i}}{s L+k C_{i}} I_{r e f}+\frac{k\left(G_{c d}-1 / k\right)}{s L+k C_{i}} V_{o}
$$

From (19), when $G_{c d}=1 / k$, the disturbance from $V_{o}$ can be eliminated, and if $k \cdot C_{i} \gg|s L|$, then $I_{L}=I_{r e f}$, identifying the accurate current control effect for $I_{r e f}$.

\section{A. Control Strategy for Any Connected Load}

Repeating the same analysis, but now considering the connection of any load between the system and the commercial electric grid, a new configuration, presented in Figure 13, is obtained. It can be observed that now the inductor current is the load current plus the utility current. Again, a sinusoidal current to the utility line is a design goal, adding a sample of the load current to the inductor current reference makes it possible to control the inductor current and still guarantee a sinusoidal utility current. A new block diagram representing the system is shown in Figure 14.

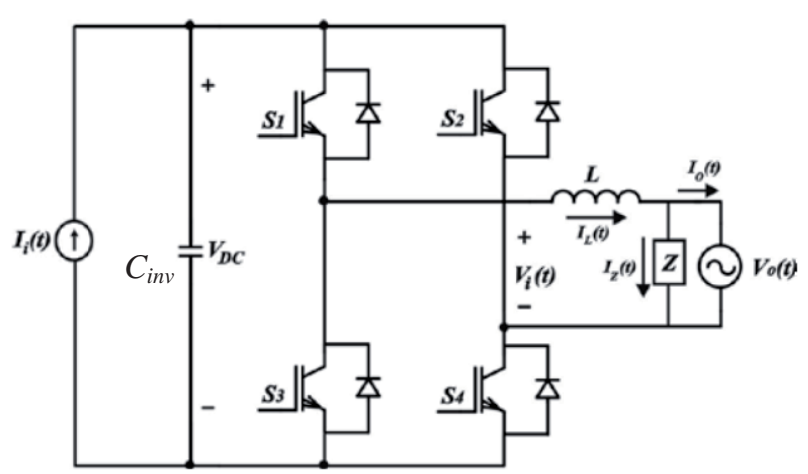

Fig. 13. PV system with any load connected.

However, in this case, besides the current sensor used to sample the current in $L$, it is necessary to add another sensor to sample the load current. Another disadvantage in this configuration is that as the control is done monitoring the load current $\left(I_{Z}\right)$, when the system is operating Active Power Line Conditioner Mode (low sun light), it is necessary to extract the fundamental component of the load current before to later find the reference current. So, it is necessary to observe at least a period of the grid.

However, sensing the AC mains current instead of the inductor current, and considering that the difference between the inductor current and the load current is the utility current, the last block diagram can be modified to represent now the utility current loop (Figure 15). Nevertheless, according to Figure $10, i_{o_{-} r e f(t)}$, or, the difference between the reference inductor current $\left(i_{\text {ref } \_}\right)$and the load current $\left(i_{Z}\right)$, is exactly $i_{o_{-} r e f}$ itself, defined by the voltage control signal multiplied by a sinusoid in phase with the utility frequency (Figure 16). Thus, the same system can be controlled by observing only the utility current $\left(I_{o}\right)$, improving the dynamics of the system, once it is not necessary any previous calculation.

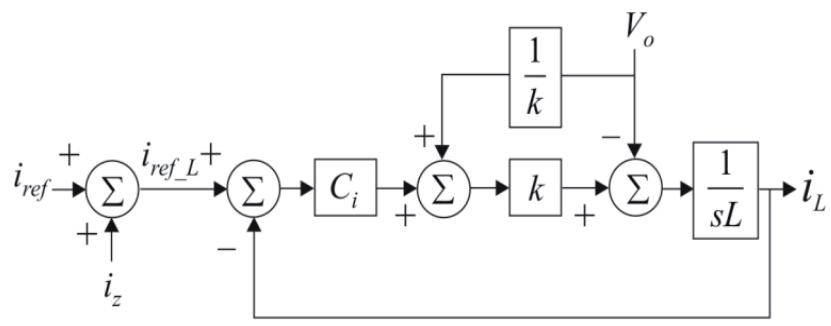

Fig. 14. New block diagram of the inductor current loop.

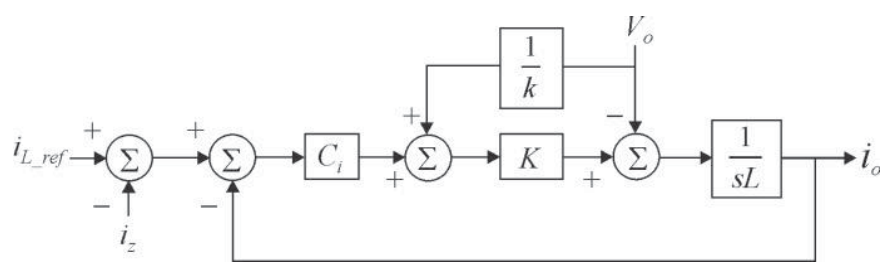

Fig. 15. Block diagram of the utility current loop. 


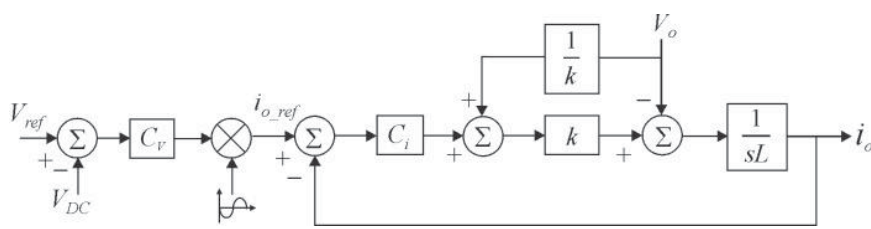

Fig. 16. Utility current control diagram.

Thus, to control the output current in phase with the utility voltage and, to obtain a high power factor, even with the connection of any kind of load between the grid and the system, it is enough to observe only the AC mains current. In this case, besides making use of a single sensor, the proposed control strategy is simpler and of easy practical implementation.

\section{EXPERIMENTAL RESULTS}

In order to demonstrate the feasibility of the discussed circuit, a prototype was designed and implemented. The specifications of the system (Figure 17 and Figure 18) are given below.

Solar array:

- Number of PV Modules: 20;

- Rated power: $1002 \mathrm{~W}$

- Rated voltage: $83.5 \mathrm{~V}$;

- Rated current: $12 \mathrm{~A}$;

- Short-circuit current: 12.4 A;

- Open-circuit voltage: $107 \mathrm{~V}$.
DC-DC power converter:

- Output power: $1200 \mathrm{~W}$

- Output voltage: $400 \mathrm{~V}$;

- Switching frequency: $100 \mathrm{kHz}$

- $C_{\text {in }}$ and $C f_{H F}: 1000 \mu \mathrm{F}$;

- $C e_{1}$ and $C e_{2}: 10 \mu \mathrm{F}$ and $5 \mu \mathrm{F}$;

- $L f_{H F}$ and $L r: 50 \mu \mathrm{H}$ and $680 \mathrm{nH}$;

- $C_{o}: 1000 \mu \mathrm{F}$

Inverter:

- Switching frequency: $20 \mathrm{kHz}$

- $C f_{L F}: 1000 \mu \mathrm{F}$;

- $L f_{L F}: 1.6 \mathrm{mH}$;

- $\mathrm{Lo}_{1}$ and $\mathrm{Lo}_{2}: 1.2 \mathrm{mH}$

- Output voltage: $220 \mathrm{~V}, 60 \mathrm{~Hz}$;

- Output Power: $1200 \mathrm{~W}$

- Load: 400 VA (Capacitive).

In the proposed system, a $L C$ filter $\left(L f_{H F}\right.$ and $\left.C f_{H F}\right)$ is connected with the PV array output to filter the high frequencies drained by the DC-DC converter, and a series $L C$ filter $\left(L f_{L F}\right.$ and $\left.C f_{L F}\right)$ is connected between the converters to support the second-order component $(120 \mathrm{~Hz})$ presented in the inverter input current.

Figure 19 and Figure 20 depicts, respectively, the load current $\left(I_{L}\right)$, the inverter current $\left(I_{o}\right)$, the utility voltage $\left(V_{U t i l i t y}\right)$ and utility current $\left(I_{S}\right)$ with the system operating just as active power line conditioning mode (cloudy day or night). In this case the first stage (DC-DC converter) does not operate. The

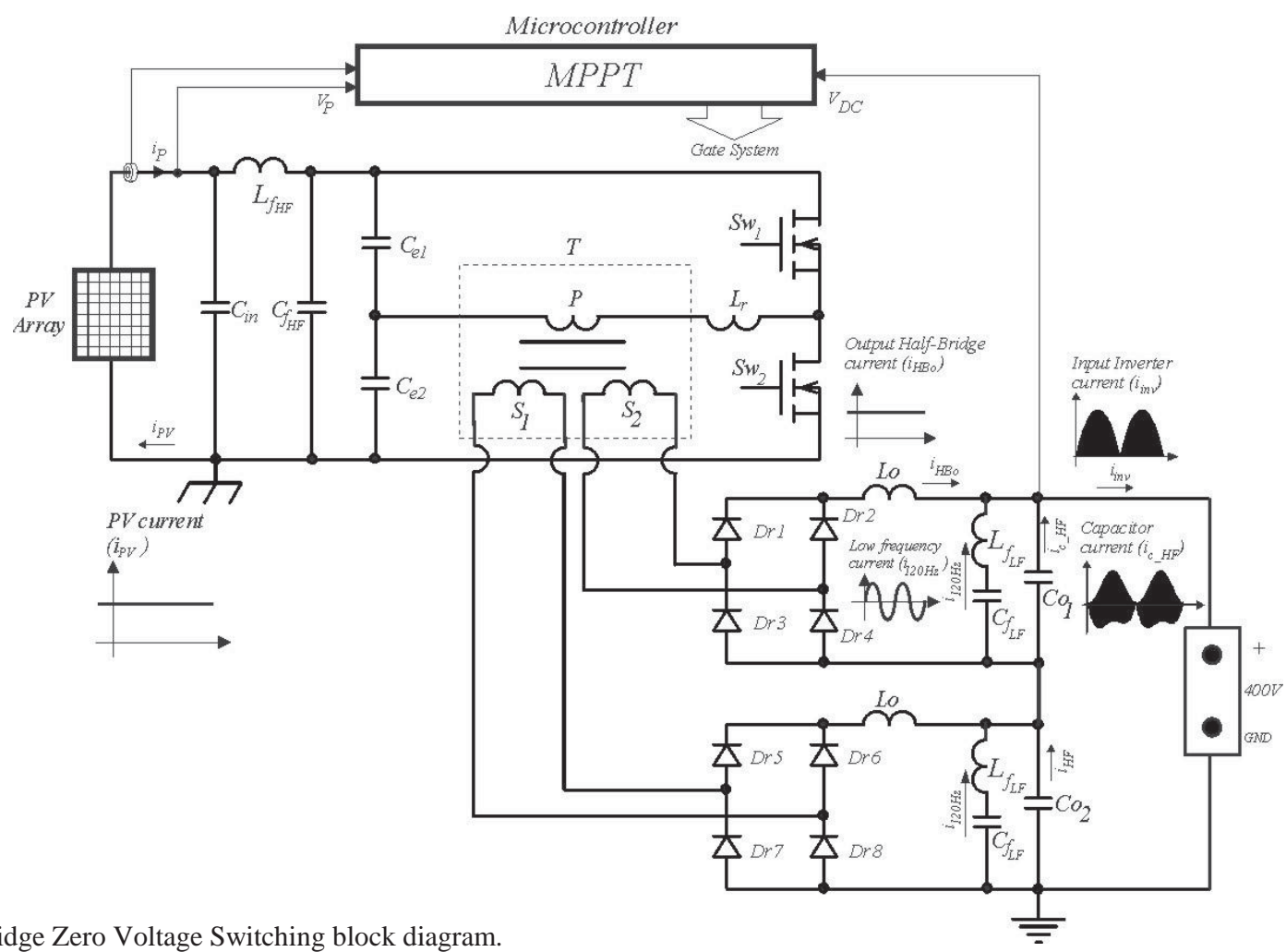

Fig. 17. Half-Bridge Zero Voltage Switching block diagram. 


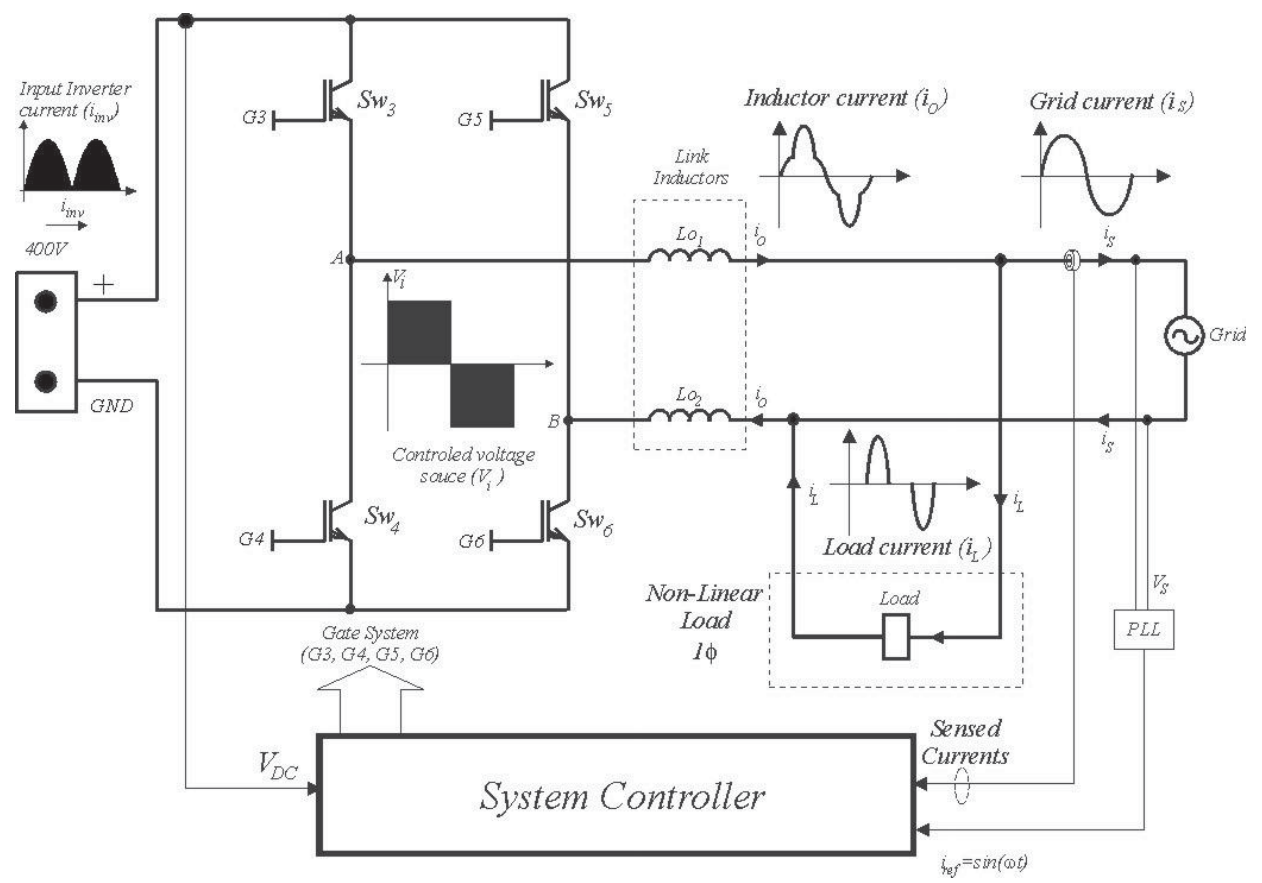

Fig. 18. Simplified block diagram of the Inverter.

THD of $I_{S}$ is $4.0 \%$ for a load crest factor of 3.09.

Figure 21 and Figure 22 depicts, respectively, the output inverter current $\left(I_{o}\right)$, the utility current $\left(I_{S}\right)$, the utility voltage and the utility current, with the system supplying power to the load and supplying surplus power to the utility grid. In this configuration, the total power delivery by the PV system is around $455 \mathrm{~W}$, where $300 \mathrm{~W}$ represent the power absorbed by the load and around $155 \mathrm{~W}$ are injected into the grid.

The current of the first stage during the starting procedure and the behavior of the converter DC bus voltage, are shown in Figure 23. At approximately $2.2 \mathrm{~s}$, the control loops operate in the system, controlling its voltage and current. Over the next $4 \mathrm{~s}$, the system goes into steady state. If the conditions of sunlight and quality of the energy are within pre-established standards, the DC-DC converter tracks the maximum power point [21]. In the proposed system the incremental conductance MPPT algorithm was implemented [22].

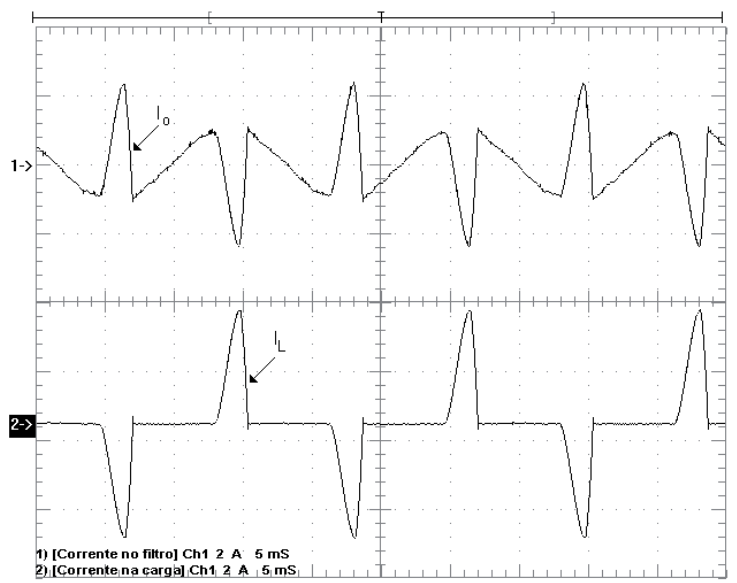

Fig. 19. Load current $\left(I_{L}\right)$ and the inverter current $\left(I_{0}\right)($ Ch1 2 A/div and Ch2 $2 \mathrm{~A} / \mathrm{div}$ ).

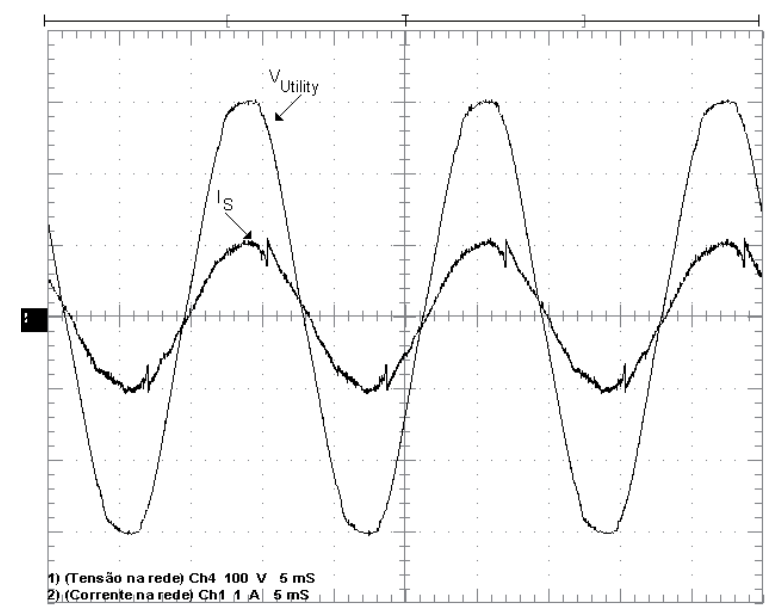

Fig. 20. Utility current $\left(\mathrm{I}_{\mathrm{S}}\right)$ and utility voltage $\left(\mathrm{V}_{\text {Utility }}\right)(\mathrm{Ch} 11 \mathrm{~A} / \mathrm{div}$ and Ch2 $100 \mathrm{~V} / \mathrm{div})$.

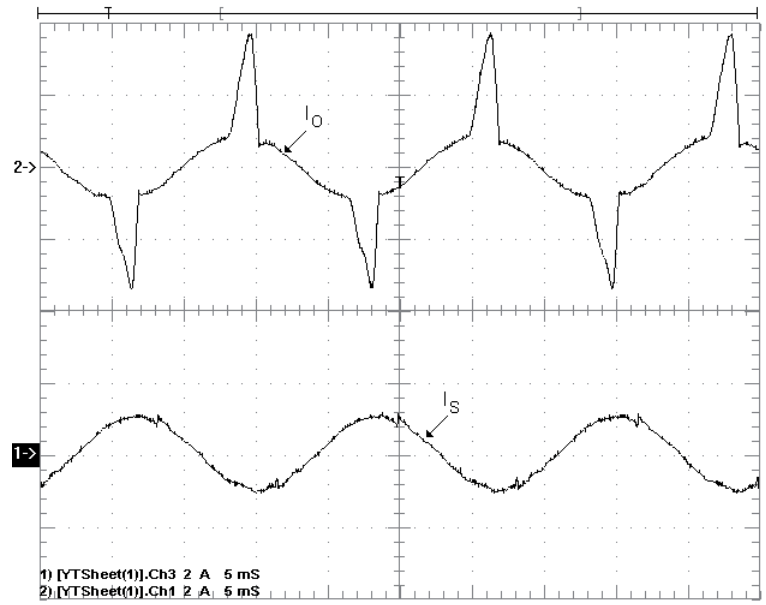

Fig. 21. Utility current $\left(\mathrm{I}_{\mathrm{S}}\right)$ and the inverter current $\left(\mathrm{I}_{\mathrm{o}}\right)(\mathrm{Ch} 12 \mathrm{~A} / \mathrm{div}$ and Ch2 $2 \mathrm{~A} / \mathrm{div})$. 


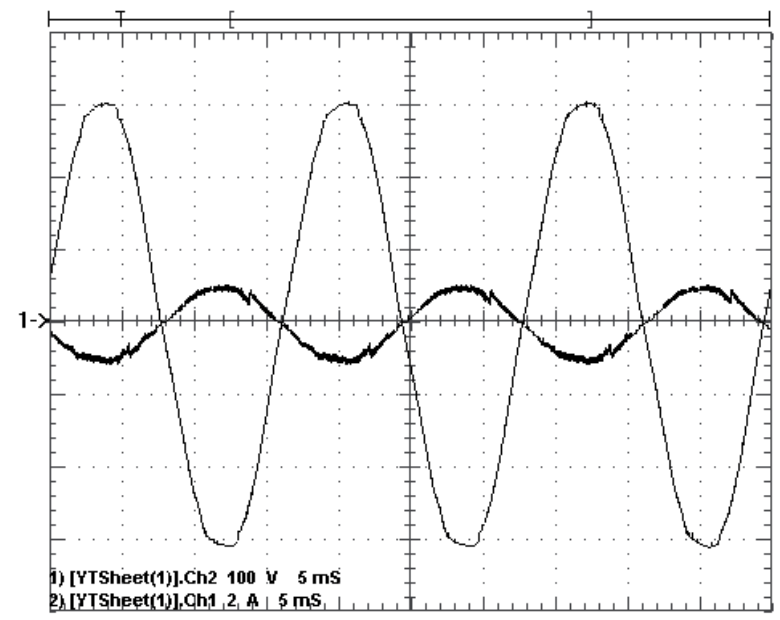

Fig. 22. Utility voltage (100 V/div) and utility current (1 A/div).

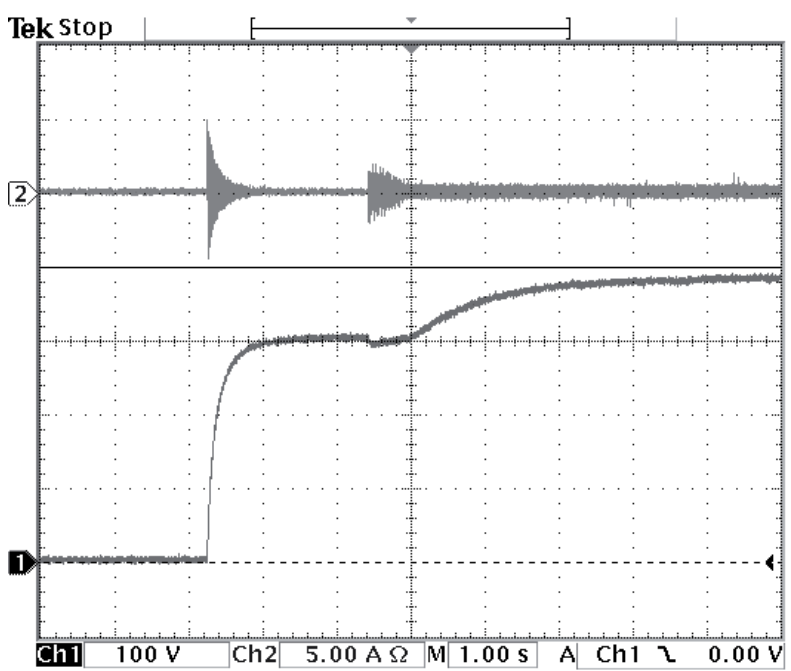

Fig. 23. DC bus voltage (lower trace $-100 \mathrm{~V} /$ div) and starting current (upper trace $1 \mathrm{~A} / \mathrm{div})$, time $1 \mathrm{~s} /$ div.

Depending on the performance of the first stage (Figure 23 ), in pursuit of the best operating condition, the grid current and the signal compensator voltage, during starting of the DC-DC converter, exhibit the behavior shown in Figure 24. As the DC-DC stage increases the power processed, the strain relief detects a tendency to increase the voltage level of the DC bus, causing an increase in control signal. Consequently, there will be an increase in the reference signal current and, therefore, in the current injected into the utility grid [21].

The shutdown of the system was also analyzed and is shown in Figure 25, where the behavior of the utility current is presented. This shutdown is triggered by pushing a power switch. At that moment, the microcontroller enters the shutdown mode and act so as to disconnect the utility grid from the PV system [21].

Figure 26 shows the utility voltage and the utility current with the system only supplying power to the utility grid (THD $=3.93 \%$ ). In this case no load is connected in the system. The total power delivery to the grid is around $400 \mathrm{~W}$.

The waveforms of voltage and current in the utility grid for the system operating at $930 \mathrm{~W}$ are shown in Figure 27. In this case the load power is $200 \mathrm{~W}$ and the power delivered to the grid is around $730 \mathrm{~W}$. The THD of the utility current is $3.83 \%$, where its harmonic spectrum is shown in Figure 28. It can be observe their agreement with international standards [23].

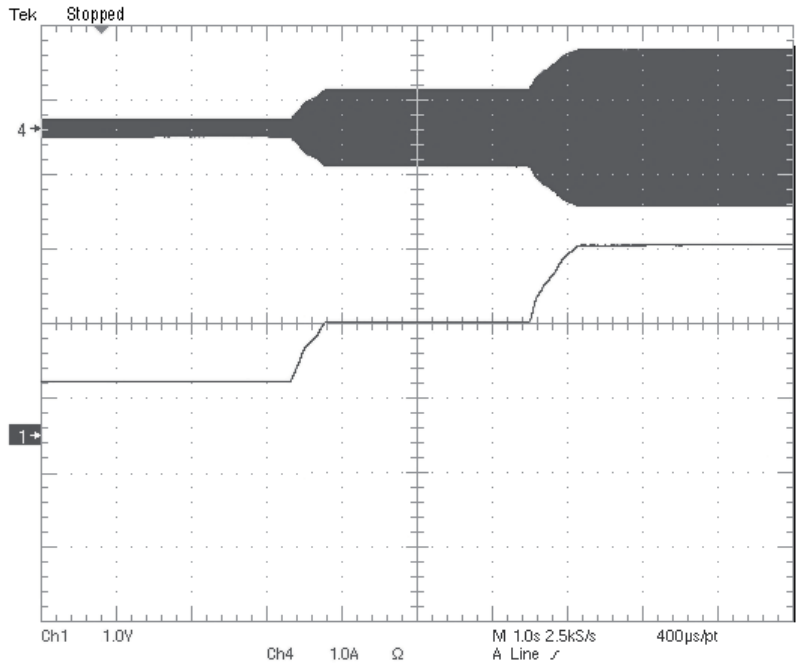

Fig. 24. Grid current (upper trace $-1 \mathrm{~A} / \mathrm{div}$ ) and signal of the voltage compensator (lower trace $1 \mathrm{~V} /$ div), time $1 \mathrm{~s} /$ div.

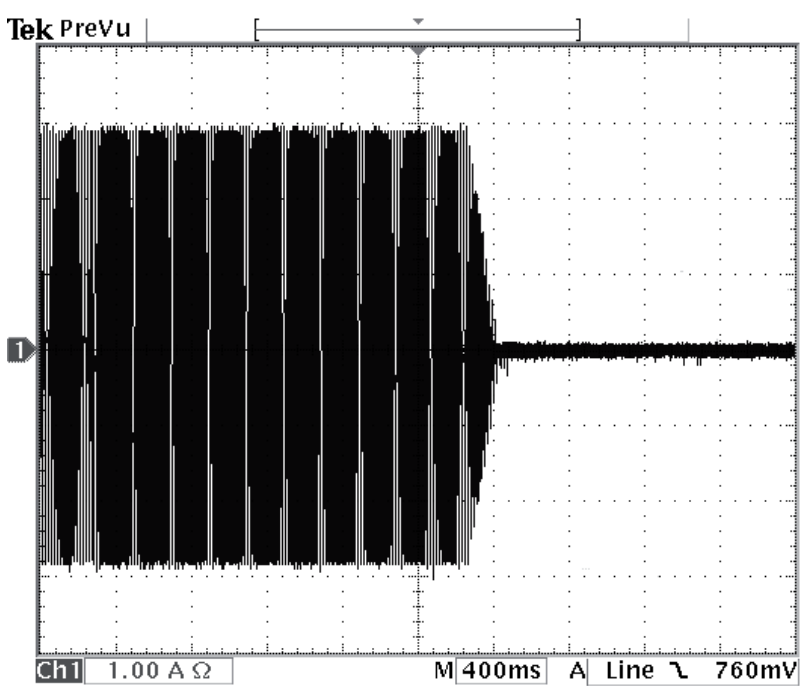

Fig. 25. Behavior of the utility current during the shutdown of the system (1 A/div; $1 \mathrm{~s} / \mathrm{div})$.

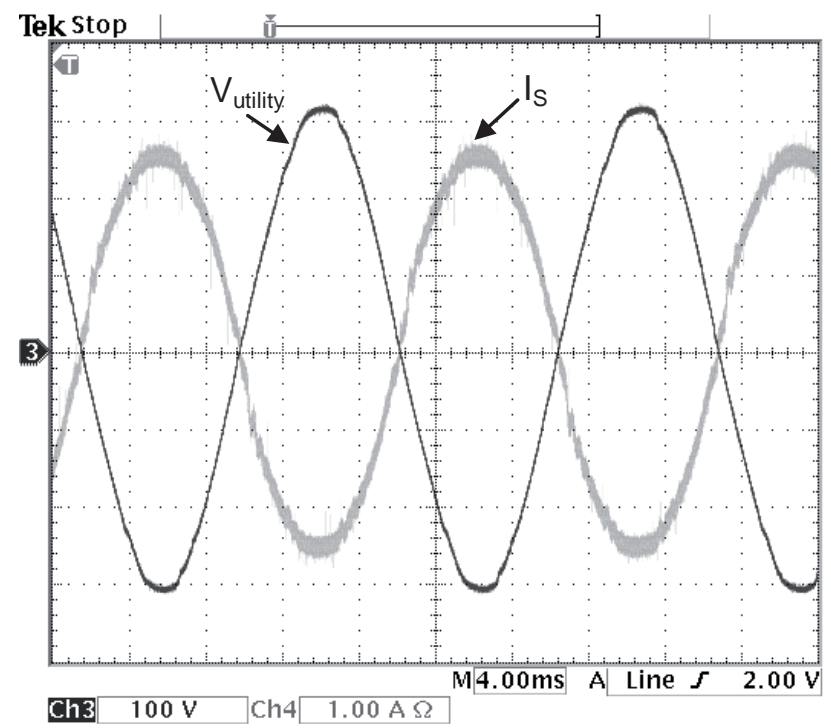

Fig. 26. Utility current $\left(\mathrm{I}_{\mathrm{S}}\right)$ and utility voltage $\left(\mathrm{V}_{\text {Utility }}\right)$ with no load (Ch1 $1 \mathrm{~A} /$ div and Ch2 $100 \mathrm{~V} / \mathrm{div}$ ). 


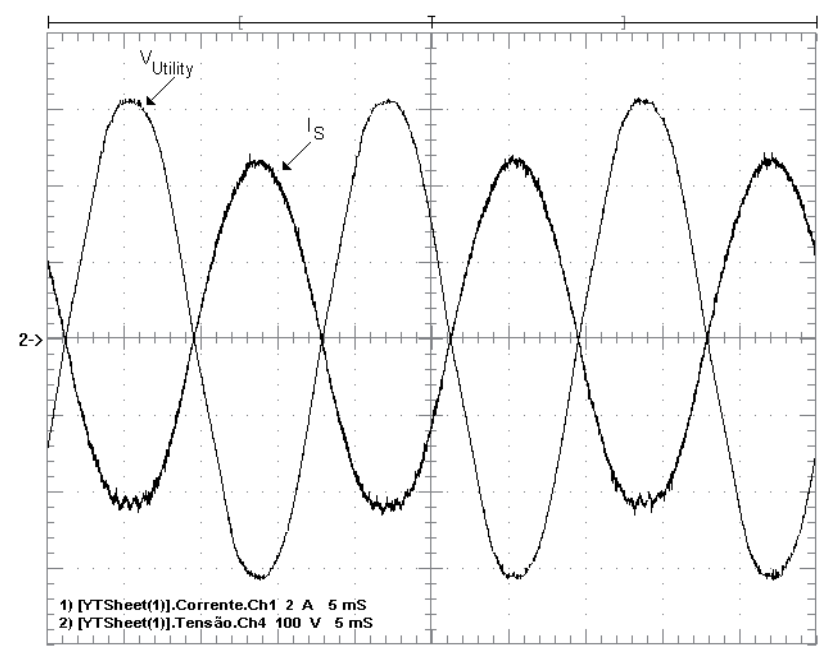

Fig. 27. Utility current $\left(\mathrm{I}_{\mathrm{S}}\right)$ and utility voltage $\left(\mathrm{V}_{\text {Utility }}\right)(\mathrm{Ch} 12 \mathrm{~A} / \mathrm{div}$ and Ch2 $100 \mathrm{~V} / \mathrm{div})$.

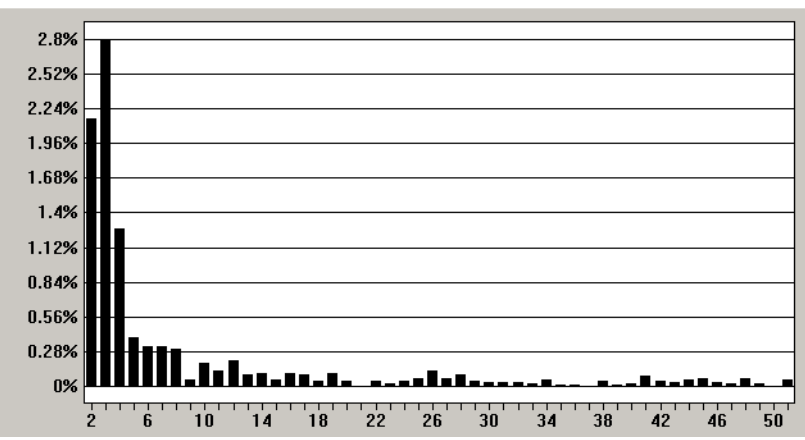

Fig. 28. Harmonic spectrum of the utility current.

Figure 29 shows the efficiency obtained from the DC-DC Half-Bridge converter. As can be seen the efficiency is around $93 \%$ to full load. The overall system efficiency was around $90 \%$.

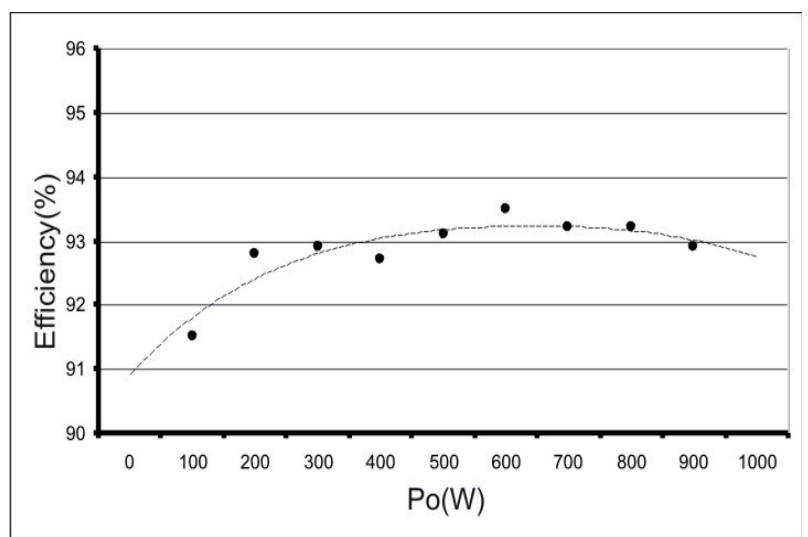

Fig. 29. Efficiency curve of the DC-DC Half-Bridge converter.

\section{CONCLUSION}

This paper presents a single-phase system for transferring photovoltaic (PV) solar power to an ac load paralleled with the utility grid. A method for minimizing the losses and the volume in the magnetic cores for the circuit also has been presented. The proposed PV system has the advantage of act as an active power filter to compensate the load harmonics and the reactive power such that the input power factor is very high, even if the load is non-linear.

The simplicity in the strategy of the output current control, in other words, current injected into the electric system, is another advantage of the proposed circuit, because besides doing use of a single current sensor, it is simpler and of easy practical implementation.

\section{ACKNOWLEDGEMENTS}

The authors would like to thank the Brazilian agencies $\mathrm{CNPq}$ and FINEP for the financial support.

\section{REFERENCES}

[1] T. Hiyama, S. Kouzuma, T. Imakubo, Identification of Optimal operation point of PV modules using neural network for real time maximum power tracking Control, IEEE Trans. Energy Conversion; vol. 10, June 1995, pp. 360-367.

[2] S. B. Kjaer, F. Blaabjerg, Design optimization of a single phase inverter for photovoltaic applications, Proc. of IEEE-PESC'03, June 13-19, 2003, Acapulco, Mexico.

[3] E. Achille, T. Martire, C. Glaize, C. Joubert, Optimize dc-ac boost converters for modular photovoltaic gridconnected generators, Proc. IEEE-ISIE'04, May 4-7, 2004, Ajaccio, France.

[4] J. P. Lee, B. D. Min, T. J. Kim, D. W. Yoo, J. Y. Yoo,. A novel topology for photovoltaic DC/DC full-bridge converter with flat efficiency under wide PV module voltage and load range, IEEE Transactions on Industrial Electronics, vol. 55 n. 8, August 2008, pp. 2655-2663.

[5] J. M. Chang, W. N. Chang, S. J. Chiang, Single-phase grid-connected PV system using three-arm rectifierinverter, IEEE Transactions on Aerospace and Electronic Systems, vol. 42, n. 1, January 2006, pp. 211-219.

[6] S. G. Tesfahunegn, A. Hajizadeh, T. M. Undeland, O.Ulleberg, P. J. S. Vie, "Modelling and control of gridconnected PV/Fuel Cell/Battery hybrid power system, "International Review on Modelling and Simulations (IREMOS), vol. 2, no. 4, pp. 381-388, Aug.2009.

[7] F. Esposito, V. Isastia, S. Meo, L. Piegari, "An improved perturb and observe algorithm for tracking maximum power points of photovoltaic power systems, "International Review on Modelling and Simulations (IREMOS)., vol. 0, no. 0, pp.10 - 16, Aug. 2008

[8] T. N. Tamer, Khatib, A. Mohamed, M. Mahmoud, N. Amin, "An efficient maximum power point tracking controller for a standalone photovoltaic system, "International Review on Modelling and Simulations (IREMOS), vol. 3, no. 2, pp. 129-139, April 2010.

[9] N. Watanakul, S. Pattanasethanon, "Performance efficiency evaluation of the electricity produced by photovoltaic cell systems of 1-5 kWp in Thailand, "International Review on Modelling and Simulations (IREMOS), vol. 3, no. 3, pp. 344-352, June 2010.

[10] X. Zhou, D. Song, Y. Ma, D. Cheng, Grid-connected control and simulation of single-phase two-level photovoltaic power generation system based on repetitive control, International Conference on Measuring 
Technology and Mechatronics Automation, March 13-14, 2010, Changsha, China.

[11] L. Cheng, R. Cheung, K. H. Leung, Advanced photovoltaic inverter with additional active power line conditioning capability, Proc. IEEE Power Electronics Specialists Conf., June 22-27, 1997, St. Louis, Missouri, USA.

[12] S. Kim, G. Yoo, J. Song, A bi-functional utility connected photovoltaic system with power factor correction and facility, Proc. Photovoltaic Specialists Conf., June 23-27, 1996, Baveno, Italy.

[13] Y. C. Kuo, T. J. Liang, J. F. Chen, Novel maximumpower-point tracking controller for photovoltaic energy conversion system, IEEE Trans. Ind. Electron., vol. 48, n. 3, June 2001, pp. 594-601.

[14] T. Wu, C. Shen, H. Nein, G. Li, A $1 \phi / 3 \mathrm{~W}$ inverter with grid connection and active power filtering based on nonlinear programming and fast-zero-phase detection algorithm, IEEE Transactions on Power Electronics, vol. 20, n. 1, January 2005, pp. 218-226.

[15] H. Lev-Ari, A. M. Stankovic, Hilbert space techniques for modeling and compensation of reactive power in energy processing systems, IEEE Transactions on Circuits and Systems I: Fundamental Theory and Applications, vol. 50, n. 4, April 2003, pp. 540-556.

[16] R. Stala, L. Stawiarski, M. Szarek, Single-phase gridconnected pv system with time-sharing modulation and pi-type regulators for dc-dc boost converter and fullbridge inverter, The 14th International Power Electronics and Motion Control Conference, EPE-PEMC 2010, September 6-8, 2010, Ohrid, Republic of Macedonia.

[17] D. C. Martins, K. C. A. de Souza, "A single-phase gridconnected PV system with active power filter", International Journal of Circuits, Systems and Signal Processing, Issue 1, vol. 2, pp. 50-55, 2008.

[18] E. Koutroulis, K. Kalaitzakis, N. C. Voulgaris, Development of a microcontroller-based photovoltaic maximum power point tracking control system, IEEE Transaction on Power Electronics, vol. 16, n. 1, April 2001, pp. 46-54.

[19] L. Zhang, A. Al-Amoudi, Y. Bai, Real-time maximum power point tracking for grid-connected photovoltaic generators, IEE Power Electronics and Variable Speed Drives Conference, September 18-19, 2000, London, UK.

[20] K. C. A. de Souza, O. H. Gonçalves, D. C. Martins, Study and optimization of two dc-dc power structures used in a grid-connected photovoltaic system, IEEE Power Electronics Specialists Conference, PESC06, June 18-22, 2006, Jeju, South Korean.

[21] K. C. A. de Souza, Study and optimization of static converters used in photovoltaic systems connected to the mains power grid, Doctoral Thesis, INEP-UFSC, August 2009, Florianopolis, SC, Brazil.

[22] C. R. Sullivan, M. J. Powers, A high-efficiency power point tracker for photovoltaic array in a solar-powered race vehicle, IEEE PESC'93, pp. 574-580, 1993.

[23] Limits for harmonic current emission (equipment input current up to and including 16 A per phase); EN 61000-32, 1995.

\section{BIOGRAPHIES}

Kleber C. A. de Souza was born in Campina Grande, PB, Brazil, in 1975. He received the B. S. and M. Sc. degrees in electrical engineering from the Federal University of Ceará, Fortaleza, Brazil, in 2000 and 2003, and Doctorate in Electric Engineering at Universidade Federal de Santa Catarina, Brazil(2009). Currently works in Federal Institute of Education, Science and Technology of Ceará, Brazil. Dr.Kleber is member of SOBRAEP.

Walbermark M. dos Santos was born in São Luis,MA, Brazil, in 1973. He received the B. S. degrees in electrical engineering from the Federal University of Maranhão, São Luis, Brazil in 2003, and M. Sc. degree in Power Electronics and Electrical Drivers from the Federal University of Santa Catarina, Florianópolis, Brazil in 2011.Currently he is a Phd Student of the Power Electronics Institute, Federal University of Santa Catarina, Brazil. Walbermark Santos is a member of SOBRAEP.

Denizar Cruz Martins was born in São Paulo, Brazil, on April 24, 1955. He received the B.S. and M.S. degrees in electrical engineering from Federal University of Santa Catarina, Florianopolis, SC, Brazil, in 1978 and 1981, respectively, and the Ph.D. degree in electrical engineering from the Polytechnic National Institute of Toulouse, Toulouse, France, in 1986. He is currently a Titular Professor in the Department of Electrical Engineering at Federal University of Santa Catarina. His interest research areas include dc-dc and dc-ac converters, high frequency, soft commutation, power factor correction and grid-connected PV systems. Dr. Denizar is a member of SOBRAEP. 